\title{
Integrative development of a short screening questionnaire of highly processed food consumption (sQ-HPF)
}

Celia Martinez-Perez ${ }^{1}$, Lidia Daimiel ${ }^{1 *}$ (10, Cristina Climent-Mainar ${ }^{1}$, Miguel Ángel Martínez-González ${ }^{2,3,4}$, Jordi Salas-Salvadó2,5,6, Dolores Corella ${ }^{2,7}$, Helmut Schröder ${ }^{8}$, Jose Alfredo Martinez ${ }^{2,9,10}$, Ángel M. Alonso-Gómez 2,11 , Julia Wärnberg 2,12 , Jesús Vioque ${ }^{13,14}$, Dora Romaguera ${ }^{2,15}$, José López-Miranda 2,16, Ramón Estruch 2,17, Francisco J. Tinahones 2,18, José Lapetra 2,19, Lluis Serra-Majem²,20, Aurora Bueno-Cavanillas ${ }^{13,21}$, Josep A. Tur ${ }^{2,22}$, Vicente Martín Sánchez ${ }^{13,23}$, Xavier Pintó ${ }^{2,24}$, Miguel Delgado-Rodríguez ${ }^{13,25}$, Pilar Matía-Martín ${ }^{26}$, Josep Vidal27,28, Clotilde Vázquez ${ }^{2,29}$, Emilio Ros²,28, Javier Basterra ${ }^{3,30}$, Nancy Babio 2,5,6, Patricia Guillem-Saiz 2,7 , María Dolores Zomeño ${ }^{8,31}$, Itziar Abete 2,10, Jessica Vaquero-Luna 2,11 , Francisco Javier Barón-López ${ }^{32}$, Sandra Gonzalez-Palacios ${ }^{13,14}$, Jadwiga Konieczna 2,15, Antonio Garcia-Rios 2,16, María Rosa Bernal-López ${ }^{33}$, José Manuel Santos-Lozano 2,19 , Maira Bes-Rastrollo 2,3, Nadine Khoury 2,5,6, Carmen Saiz ${ }^{2,7}$, Karla Alejandra Pérez-Vega ${ }^{8}$, María Angeles Zulet ${ }^{2,10}$, Lucas Tojal-Sierra ${ }^{2,11}$, Zenaida Vázquez Ruiz ${ }^{2,3}$, Maria Angeles Martinez ${ }^{2,5,6}$, Mireia Malcampo ${ }^{8}$, José M. Ordovás ${ }^{1,34}$ and Rodrigo San-Cristobal ${ }^{9}$

\begin{abstract}
Background: Recent lifestyle changes include increased consumption of highly processed foods (HPF), which has been associated with an increased risk of non-communicable diseases (NCDs). However, nutritional information relies on the estimation of HPF consumption from food-frequency questionnaires (FFQ) that are not explicitly developed for this purpose. We aimed to develop a short screening questionnaire of HPF consumption (sQ-HPF) that integrates criteria from the existing food classification systems.

Methods: Data from 4400 participants (48.1\% female and 51.9\% male, $64.9 \pm 4.9$ years) of the Spanish PREDIMED-Plus ("PREvention with MEDiterranean Dlet") trial were used for this analysis. Items from the FFQ were classified according to four main food processing-based classification systems (NOVA, IARC, IFIC and UNC). Participants were classified into tertiles of HPF consumption according to each system. Using binomial logistic regression, food groups associated with agreement in the highest tertile for at least two classification systems were chosen as items for the questionnaire. ROC analysis was used to determine cut-off points for the frequency of consumption of each item, from which a score was calculated. Internal consistency of the questionnaire was assessed through exploratory factor analysis (EFA) and Cronbach's analysis, and agreement with the four classifications was assessed with weighted kappa coefficients.
\end{abstract}

\footnotetext{
${ }^{*}$ Correspondence: lidia.daimiel@imdea.org

${ }^{1}$ Nutritional Genomics and Epigenomics Group, Precision Nutrition

and Obesity Program, IMDEA Food, CEI UAM + CSIC, Ctra. Cantoblanco, 8,

28049 Madrid, Spain

Full list of author information is available at the end of the article
}

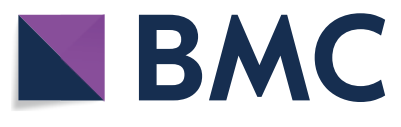

Ther(s) 2022. Open Access This article is licensed under a Creative Commons Attribution 4.0 International License, which permits use, sharing, adaptation, distribution and reproduction in any medium or format, as long as you give appropriate credit to the original author(s) and the source, provide a link to the Creative Commons licence, and indicate if changes were made. The images or other third party material in this article are included in the article's Creative Commons licence, unless indicated otherwise in a credit line to the material. If material is not included in the article's Creative Commons licence and your intended use is not permitted by statutory regulation or exceeds the permitted use, you will need to obtain permission directly from the copyright holder. To view a copy of this licence, visit http://creativecommons.org/licenses/by/4.0/. The Creative Commons Public Domain Dedication waiver (http://creativeco mmons.org/publicdomain/zero/1.0/) applies to the data made available in this article, unless otherwise stated in a credit line to the data. 
Results: Regression analysis identified 14 food groups (items) associated with high HPF consumption for at least two classification systems. EFA showed that items were representative contributors of a single underlying factor, the "HPF dietary pattern" (factor loadings around 0.2). We constructed a questionnaire asking about the frequency of consumption of those items. The threshold frequency of consumption was selected using ROC analysis. Comparison of the four classification systems and the sQ-HPF showed a fair to high agreement. Significant changes in lifestyle characteristics were detected across tertiles of the SQ-HPF score. Longitudinal changes in HPF consumption were also detected by the sQ-HPF, concordantly with existing classification systems.

Conclusions: We developed a practical tool to measure HPF consumption, the SQ-HPF. This may be a valuable instrument to study its relationship with NCDs.

Trial registration: Retrospectively registered at the International Standard Randomized Controlled Trial Registry (ISRCTN89898870) on July 24, 2014.

Keywords: Ultra-processed food, Highly processed food, Questionnaire, PREDIMED-Plus, NOVA, Food processingbased classification

\section{Background}

Changes in eating patterns are occurring worldwide [1]. A common feature of such changes is the transition from minimally processed food to moderately processed to highly processed (HPF) or ultra-processed foods (UPF) [2-10]. A widely used, although controversial [11], definition of UPF is that these are "industrial formulations made mostly or entirely from substances derived from foods and additives, with little if any intact food" [12]. According to the NOVA classification system, these foods are highly palatable and habit-forming, microbiologically safe, affordable, strongly marketed and advertised, and sold in convenient and attractive packaging, promoting their overconsumption $[12,13]$. This, together with the evidence showing their negative impact on health $[9,10,14-18]$, has turned UPF consumption into a potential public health concern [19] in need of more solid research. While the term UPF is mainly attributed to the NOVA system, other food processing-based classification systems have described foods and drinks of similar characteristics under their categories of HPF [20,21], so we will use the term HPF to refer to this type of foods.

Although numerous studies have demonstrated a link between the risk of developing non-communicable diseases and HPF consumption [12, 17, 22-27], epidemiological research faces some hurdles in this field. First, the existence of multiple food processing-based classification systems based on different criteria $[21,28]$ results in heterogeneous conclusions regarding health outcomes depending on the system used, as shown recently for cardiometabolic health markers [20]. Second, the lack of an effective tool to assess HPF consumption in clinical studies severely hinders the downstream analysis of its relationship to disease risk. For instance, in the PREDIMED-Plus (from the Spanish "PREvention with MEDiterranean DIet") trial, dietary intake was assessed through a lengthy food frequency questionnaire (FFQ).
Therefore, estimation of HPF consumption requires the classification of FFQ items according to the selected classification system, as previously done $[20,24,25$, 29]. This process is time-consuming and subject to bias on the part of the researcher classifying the items since FFQs are not specifically designed to include HPF. This is because an FFQ is designed to estimate consumption of general commonly consumed foods, of which some may fall into the HPF category, but this depends on the classification system used [20]. In addition, calculations of daily consumption of each HPF item and percentage over total intake (in grams or kcal per day) are commonly used to infer their association with health outcomes $[9$, 17, 30]. These calculations are not direct and time-consuming when derived from current tools such as FFQs or $24 \mathrm{~h}$ recalls. There is, therefore, the need for an easy-touse and comprehensive measure that assesses HPF consumption in the general population. This paper describes the development of a new screening questionnaire that allows an easy and quick determination of a subject's HPF consumption, the sQ-HPF. We view this as an integrative tool since it incorporates criteria from four foodprocessing-based classification systems. We developed this questionnaire based on available data from an FFQ to create a tool that could replace the estimation of HPF consumption from FFQ in future studies. We hypothesize that the $\mathrm{sQ}-\mathrm{HPF}$ is comparable in terms of evaluating HPF consumption to other dietary assessment tools that must be used in combination with food processing-based classification systems and can effectively capture longitudinal changes in HPF consumption.

This questionnaire will be of potential interest to the scientific community, especially in the context of clinical nutrition and public health. Its use should minimize the difficulty in comparing results from studies that use different classification systems, allowing a straightforward evaluation of the HPF dietary pattern in large 
epidemiological studies efficiently and comparably. Altogether, it will enable the development of tailored nutritional interventions and food policies to limit HPF consumption and prevent diet-related diseases.

\section{Methods Study population}

Data from the PREDIMED-Plus trial (from the Spanish "PREvention with MEDiterranean DIet") was used. This is an ongoing 6-year, multicenter, randomized, parallelgroup clinical trial launched in Spain in 2013. The main aim of the study is to evaluate the effect on primary cardiovascular disease prevention of an intensive weight loss and its long-term maintenance through a lifestyle intervention based on three pillars: energy-restricted Mediterranean diet (er-MedDiet), increased physical activity (PA) and behavioral support. The study protocol, including study design and data collection, can be found at the PREDIMED-Plus website (https://www.predimedpl us.com/en/) and was approved according to the ethical standards of the Declaration of Helsinki by the Institutional Review Boards (IRBs) of all participating centers. All participants provided written consent for their participation in the study. The trial is conducted in 23 Spanish centers and involves 6874 participants (48.5\% female, $54.5 \%$ male) between 55 and 75 years old (mean age and SD $65.0 \pm 4.9)$ who presented with overweight or obesity $\left(\mathrm{BMI} \geq 27\right.$ and $<40 \mathrm{~kg} / \mathrm{m}^{2}$ ) and met at least three criteria for metabolic syndrome (MetS) as previously described [31]. Details about the cohort have been described elsewhere [32]. The trial was retrospectively registered at the International Standard Randomized Controlled Trial Registry with number 89898870 on 24th July 2014. The present analysis used baseline and longitudinal (years 1 and 2) data from the PREDIMED-Plus study data set dated 26th June 2020 was used. Participants with implausible energy intakes $(<500$ or $>3500 \mathrm{kcal}$ for females and $<800$ or $>4000 \mathrm{kcal}$ for males) were excluded. In addition, participants with missing values for dietary, lifestyle and socioeconomic variables were not included in the analysis. After the definition of the tertile agreement variable (see Statistical analyses section), participants with (1) no coincidence in extreme tertiles of HPF consumption (either in tertile 1 or tertile 3 ) according to at least two classification systems and (2) participants that were classified in tertile 1 for two classification systems and tertile 3 for the other two classification systems were excluded. This was done to select extreme HPF consumers to further construct the binomial regression model. The final number of participants included in the analysis for the development of the questionnaire was 4400 (48.1\% female and $51.9 \%$ male, $64.9 \pm 4.9$ years) (Fig. 1 ).
This study adhered to the STROBE-nut reporting guidelines [33].

\section{Blood measurements}

Trained nurses collected blood samples after overnight fasting at the recruiting centers or primary health care centers. Plasma glucose, triglycerides and total cholesterol levels were measured following standard enzymatic methods.

\section{Anthropometric measurements}

Weight and waist circumference measurements were taken from participants in light clothing with no shoes or accessories, using an electronic calibrated scale and an anthropometric tape, respectively. Waist circumference was measured midway between the lowest rib and the iliac crest. Height measurements were taken using a wallmounted stadiometer. Body Mass Index (BMI) was calculated as the weight in kilograms divided by the square of height in meters.

\section{Lifestyle measurements}

Socioeconomic and PA data were collected through the general PREDIMED-Plus questionnaire. Based on the validated questionnaires, the REGICOR [34] and the Rapid Assessment of Physical Activity (RAPA) [35], participants were asked about the frequency and intensity of physical activities, and three levels of PA were defined as follows: low (frequent sitting and little walking and/or frequent sitting and moderate sustained efforts), medium (frequent walking with no vigorous efforts), high (frequent walking and vigorous efforts and/or frequent vigorous efforts). Sedentary behaviors were assessed through a validated questionnaire, the Spanish version of the Nurses' Health Study (NHS) questionnaire [36]. Data about eating habits (binge eating, snacking) were collected within the multidimensional scale of weight locus control questionnaire [37]. Trained interviewers administered questionnaires in individual face-to-face sessions.

\section{Dietary measurements}

To assess the dietary intake of participants over the last year, a validated semi-quantitative 143-item FFQ [3840] that considers variations in dietary patterns among seasons, weekdays and weekends was used. Participants were asked the average frequency of consumption of a commonly used portion size (e.g., glass, cup, slice) for each food or beverage item. Nine options for frequency of consumption are given, ranging from "never or hardly ever" to "more than six times a day." To estimate the daily consumption for each item, the portion size was multiplied by the frequency of consumption and then expressed as grams per day. This calculation 


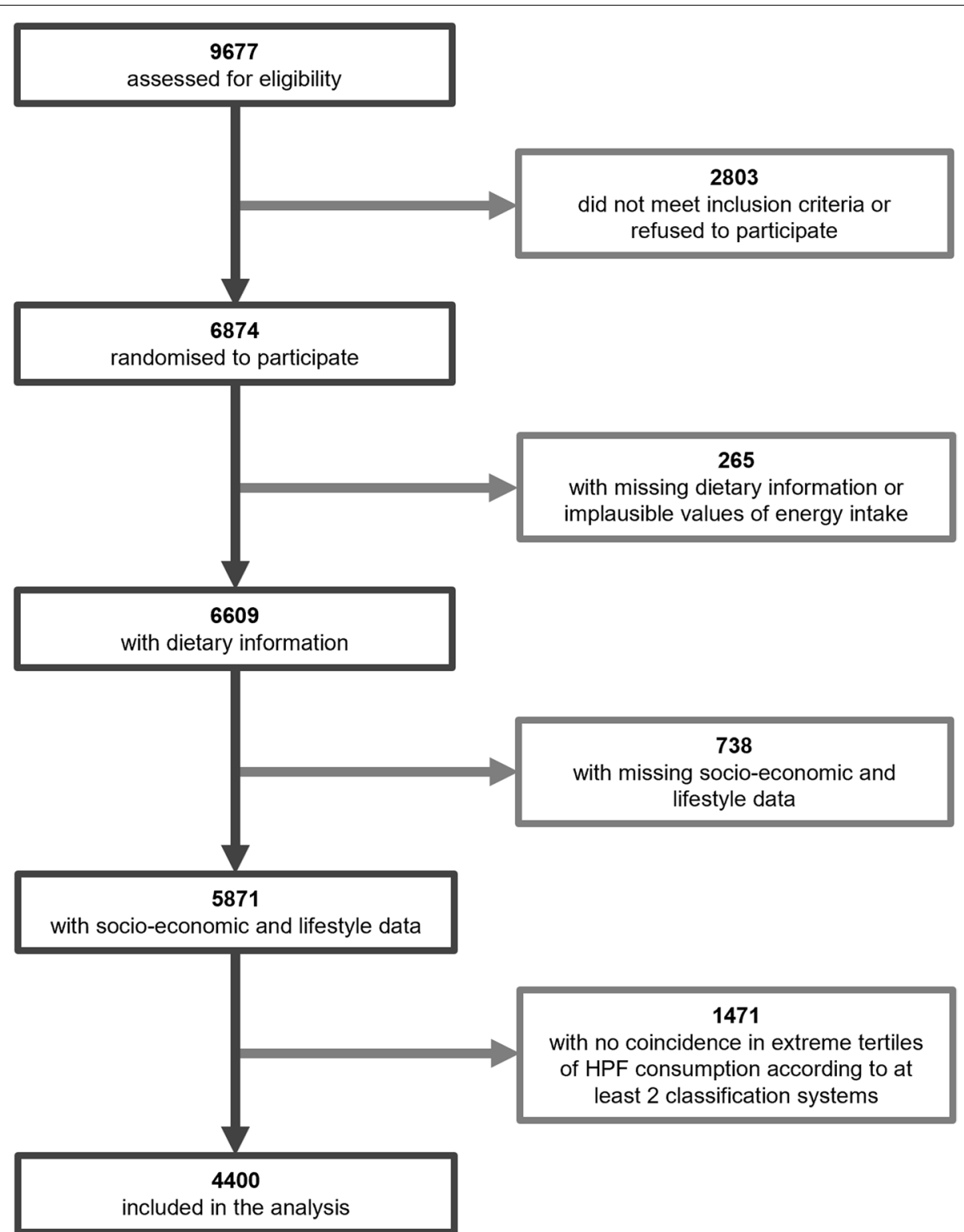

Fig. 1 Flowchart of the PREDIMED-Plus participants. Number of subjects shown in bold

was not possible for the fried foods item as the portion size is not specified in the FFQ. To assess adherence to an er-MedDiet, a 17-item questionnaire specially developed and validated for the PREDIMED-Plus trial $[41,42]$ was used. Through this questionnaire, the frequency of consumption of traditional Mediterranean food items is evaluated. One point is scored when the answer meets specific criteria defining er-MedDiet, so the higher the score, the better adherence to this diet.
HPF consumption and food processing-based classification systems

Four food-processing based classification systems the NOVA [12, 43, 44], the International Agency for Research on Cancer (IARC) [7, 45], the International Food Information Council Foundation (IFIC) [46, 47], and the University of North Carolina (UNC) [48] systems - were used to classify FFQ items into processing categories as previously described [20]. In the present 
study, HPF refers to the following groups: Group 4 for NOVA, Group 3 for IARC, Groups 4 and 5 for IFIC, and Groups 4.1 and 4.2 for UNC. For each participant, HPF consumption was estimated according to each classification system as the sum of grams per day consumed from foods in the HPF group, divided by the total grams of food consumed per day and multiplied by 100 [20]. The frequency of consumption was directly obtained from FFQ answers in times per day.

\section{Statistical analyses}

Data analysis was conducted using $\mathrm{R}$ programming language [49] in RStudio [50] and with the following statistical packages: "DescTools" [51], "psych" [52], "tableone" [53], "cutpointr" [54], "corrplot" [55], "vcd" [56] and rstatisx [57]. Participants were classified according to tertiles of HPF consumption for each classification system (T1 - low HPF consumption, T3 high HPF consumption). Tertiles were chosen to capture and show the variability in HPF consumption while allowing a straightforward comparison between classification systems. Then, subjects were classified according to tertile agreement for, at least, two classification systems. Those classified in T3 in at least two classification systems scored "1" for tertile agreement, while those classified in T1 for at least two classification systems scored "0". FFQ items were classified into food groups according to their similar nature, nutritional characteristics, and/or form of consumption (Supplementary Table 1). The association between tertile agreement and frequency of consumption for each food group was analyzed through binomial logistic regression, adjusted for age, sex, recruitment center, energy intake, physical activity level, medication for blood pressure and diabetes, working status, educational level, and civil status, using the "glm" function from $\mathrm{R}$ base package "stats." These covariates were selected due to their potential effect on HPF consumption. To calculate optimal cut-off points of frequency of consumption for the selected items, receiver operating characteristic (ROC) analysis was performed using the R package "cutpointr" and the "cutpointr" function [54]. The method to estimate the cut-off points was based on the maximization of the Youden-Index [58]. Estimated cut-off points were used to establish the criteria for scoring 1 point in the sQ-HPF, which indicated high HPF consumption, or 0 , indicating low HPF consumption. Cut-off points were adapted to the nine possible answers of the FFQ, so the criteria for scoring were based on a threshold frequency of consumption for each item (i.e., food group). In parallel, exploratory factor analysis (EFA) was performed to identify underlying relationship patterns between items included in the SQ-HPF using the "fa" function from the "psych" package [52]. To test for data suitability for the
EFA, the Kaiser-Meyer-Olkin Criterion [59] and Bartlett's test of sphericity [60] were applied. The EFA was performed without rotation and with a principal factor solution as a factoring method. Factor retention was based on the scree plot and Kaiser's criterion [61]. Cronbach's alpha [62] was calculated as a measure of internal consistency of the questionnaire. Using the criteria for scoring, the sQ-HPF score was calculated for each subject in the PREDIMED-Plus database, and the questionnaire estimated HPF consumption was calculated through linear regression analysis using the sQ-HPF score as the dependent variable. For descriptive analyses, participants were classified into tertiles of the sQ-HPF score. Data is shown in tables as "mean (standard deviation, SD)" for continuous variables and as "number of subjects (\%)" for categorical variables. Statistically significant differences $(p<0.05)$ in dietetic and lifestyle variables among tertiles were compared using a one-way ANOVA test for continuous variables and a Chi-squared test for categorical variables. $P$-values were adjusted for age, sex, recruitment center, energy intake, physical activity level, medication for blood pressure and diabetes, working status, educational level, and civil status. To assess the concordance between tertiles of HPF consumption calculated by the four classification systems and by the sQ-HPF, weighted Cohen's kappa ( $\mathrm{k}$ ) coefficients were calculated with the function "Kappa" from the $\mathrm{R}$ package "vcd". For longitudinal analysis of HPF consumption, a linear mixed model was performed using the $\mathrm{R}$ package "lme4" and "emmeans" with the same covariates as previous analyses. The number of subjects used for this analysis was 3284 due to longitudinal data loss.

\section{Results}

\section{General characteristics of the PREDIMED-Plus cohort} according to tertile agreement

Subjects scored 1 in the tertile agreement variable if they were classified in the highest tertile (T3) of HPF consumption for at least two classifications systems, while they scored 0 if they were classified in the lowest tertile (T1) of HPF consumption for at least two classifications systems. General characteristics of PREDIMED-Plus participants at baseline according to the scores of the tertile agreement variable are shown in Table 1. Subjects who scored 1 (high HPF consumption by at least two classification systems) were mainly men (73.1\%), had higher energy intake $(2559.84 \mathrm{kcal} /$ day) and lower MedDiet adherence ( 7.65 points) than subjects who scored 0 (low HPF consumption by at least two classifications systems). Among the high HPF subjects, $78.8 \%$ were married and $41.8 \%$ had a primary education level. Around half of the subjects who scored 1 showed a low level of PA (55.3\%) and were taking medication for cholesterol (49.8\%). 
Table 1 General characteristics of PREDIMED-Plus participants at baseline according to tertile agreement

\begin{tabular}{|c|c|c|c|}
\hline & \multicolumn{2}{|c|}{ Tertile agreement $^{\mathrm{a}}$} & \multirow[b]{2}{*}{$p$} \\
\hline & Low HPF & High HPF & \\
\hline $\mathbf{n}$ & 2186 & 2214 & \\
\hline Age (years) & $66.14(4.50)$ & $63.68(5.07)$ & $<0.001$ \\
\hline Female sex (\%) & $1522(69.6)$ & $595(26.9)$ & $<0.001$ \\
\hline Civil status (\%) & & & 0.001 \\
\hline Single & $115(5.3)$ & $109(4.9)$ & \\
\hline Married & $1622(74.2)$ & $1745(78.8)$ & \\
\hline Widowed/divorced & $449(20.5)$ & $360(16.3)$ & \\
\hline \multicolumn{4}{|l|}{ Education level (\%) } \\
\hline Primary & $1252(57.3)$ & $926(41.8)$ & $<0.001$ \\
\hline Secondary & $538(24.6)$ & $704(31.8)$ & \\
\hline College & $396(18.1)$ & $584(26.4)$ & \\
\hline Active working status (\%) & $307(14.0)$ & $642(29.0)$ & $<0.001$ \\
\hline Energy intake (kcal/day) & $2158.46(480.16)$ & $2559.84(571.11)$ & $<0.001$ \\
\hline MedDiet adherence score & $9.46(2.54)$ & $7.65(2.61)$ & $<0.001$ \\
\hline PA level (\%) & & & 0.001 \\
\hline Low & $1188(54.3)$ & $1225(55.3)$ & \\
\hline Medium & $904(41.4)$ & $841(38.0)$ & \\
\hline High & $94(4.3)$ & $148(6.7)$ & \\
\hline Blood pressure medication (\%) & $1717(78.5)$ & $1676(75.7)$ & 0.027 \\
\hline Cholesterol medication (\%) & $1123(51.4)$ & $1102(49.8)$ & 0.303 \\
\hline Diabetes medication (\%) & $631(28.9)$ & $573(25.9)$ & 0.029 \\
\hline
\end{tabular}

Data shown as "mean (standard deviation, SD)" for continuous variables and as "number of subjects (\%)" for categorical variables. One-way ANOVA test used for continuous variables and Chi-squared test used for categorical variables. Significant $p$-values $(<0.05)$ shown in bold

MedDiet Mediterranean diet, PA Physical activity

a Tertile agreement variable: score 0 - "low HPF consumer" if a subject is classified in T1 of HPF consumption by at least two classification systems; score 1 - "high HPF consumer" if a subject is classified in T3 by at least two classification systems. HPF: highly processed food. $N=4400$

In addition, $75.7 \%$ of them were taking medication for blood pressure and $25.9 \%$ were on diabetes medication. According to these results, the variables age, sex, recruitment center, energy intake, physical activity level, medication for blood pressure and diabetes, working status, educational level, and civil status were selected as covariates for further analysis due to their potential effect on HPF consumption. MedDiet adherence was not selected as a covariate due to the presence of collinearity with HPF consumption.

\section{Development of the SQ-HPF}

Food groups were defined based on the similarity in nature, nutritional profile and/or form of consumption of the PREDIMED-Plus FFQ food and beverage items (Supplementary Table 1). Food groups chosen to be included in the sQ-HPF showed a significant positive association (p-value adjusted by Bonferroni $<0.05$ ) between their frequency of consumption and a value of 1 of tertile agreement, i.e., the subject is in tertile 3 of HPF consumption for at least two food processing-based classification systems (Table 2). A final solution of 14 food groups was selected and included the following: fatty dairy products, sugary dairy products, cured meat, fats, fermented alcohol, distilled alcohol, sugary and artificially sweetened drinks, sweets, snacks, ready to eat products, refined cereals, sauces, additives, and fried foods.

EFA revealed that most of the items selected for the sQ-HPF had factor loadings higher than 0.2, indicating that they were representative contributors to the factor (Table 3). The measure of sample adequacy (MSA) was 0.78 , considered as "good" for the verification of the proportion of variance in variables that can be caused by factors, according to the Kaiser-Meyer-Olkin Criterion. Bartlett's test of sphericity was highly significant $(p<0.001)$, indicating that variables were correlated in the population. This, together with the MSA value, indicated the adequacy of the data to proceed with EFA. Factor retention applying the Kaiser criterion revealed a single underlying factor being identified by the questionnaire items, namely the HPF dietary pattern. The internal consistency of the questionnaire items was evaluated with Cronbach's alpha, which had a moderate value of 0.67 . 
Table 2 Associations between candidate sQ-HPF items and tertile agreement variable by binomial logistic regression

\begin{tabular}{|c|c|c|c|}
\hline Predictor variable & $\beta$ & SE & $p($ Bonf $)$ \\
\hline Fatty dairy products & 0.33 & 0.10 & 0.024 \\
\hline Sugary dairy products & 1.37 & 0.22 & $<0.001$ \\
\hline Cured meat & 0.59 & 0.07 & $<0.001$ \\
\hline Fats & 0.63 & 0.14 & 0.001 \\
\hline Fermented alcohol & 1.59 & 0.07 & $<0.001$ \\
\hline Distilled alcohol & 3.90 & 0.45 & $<0.001$ \\
\hline Sugary drinks & 3.90 & 0.17 & $<0.001$ \\
\hline Sweets & 0.46 & 0.05 & $<0.001$ \\
\hline Snacks & 3.93 & 0.43 & $<0.001$ \\
\hline Ready To Eat (RTE) & 2.91 & 0.33 & $<0.001$ \\
\hline Refined cereals & 0.30 & 0.04 & $<0.001$ \\
\hline Sauces & 0.97 & 0.18 & $<0.001$ \\
\hline Additives & 0.10 & 0.02 & $<0.001$ \\
\hline Fried food & 0.84 & 0.15 & $<0.001$ \\
\hline Whole dairy products & -0.01 & 0.06 & 1 \\
\hline Semi-skimmed dairy products & -0.15 & 0.03 & $<0.001$ \\
\hline Eggs & -0.31 & 0.19 & 1 \\
\hline Red meat & 0.05 & 0.15 & 1 \\
\hline White meat & -1.41 & 0.17 & $<0.001$ \\
\hline White fish & -1.40 & 0.16 & $<0.001$ \\
\hline Blue fish & -1.29 & 0.15 & $<0.001$ \\
\hline Vegetables & -0.55 & 0.03 & $<0.001$ \\
\hline Fruit & -1.01 & 0.04 & $<0.001$ \\
\hline Potatoes & -0.88 & 0.18 & $<0.001$ \\
\hline Nuts & -0.87 & 0.07 & $<0.001$ \\
\hline Legumes & -2.46 & 0.23 & $<0.001$ \\
\hline Oils & -0.21 & 0.03 & $<0.001$ \\
\hline Non-sugary drinks & -0.09 & 0.03 & 0.302 \\
\hline Wholegrain cereals & -0.53 & 0.04 & $<0.001$ \\
\hline Vitamin/supplements & -0.10 & 0.12 & 1 \\
\hline Binge eating & 0.17 & 0.14 & 1 \\
\hline $\mathrm{N}^{\circ}$ binges/week & 0.05 & 0.05 & 1 \\
\hline Snacking & 0.06 & 0.08 & 1 \\
\hline
\end{tabular}

Binomial logistic regression adjusted for age, sex, recruitment center, energy intake, physical activity level, medication for blood pressure and diabetes, working status, educational level, and civil status. Tertile agreement is the outcome variable (score 0 - "low HPF consumer" if a subject is classified in T1 of HPF consumption by at least two classification systems; score 1 - "high HPF consumer" if a subject is classified in T3 by at least two classification systems). Food groups expressed in frequency of consumption (times/day). HPF: highly processed food. Items selected for the SQ-HPF are shown in bold. Bonf: Bonferroni adjustment. $N=4400$

The sQ-HPF was based on the 14 food groups selected previously. Each item asked about the frequency of consumption of a particular food group (Table 4). Examples of representative food and beverage items included in each food group were provided for each item. Estimated cut-off points were used to determine the threshold frequency of consumption to consider the respondent as an
Table 3 Exploratory factor analysis for sQ-HPF items

\begin{tabular}{ll}
\hline Factor 1: HPF diet & Factor loadings \\
\hline Ready To Eat (RTE) & 0.45 \\
Fried food & 0.44 \\
Fermented alcohol & 0.42 \\
Snacks & 0.42 \\
Fatty dairy products & 0.38 \\
Sugary drinks & 0.37 \\
Distilled alcohol & 0.36 \\
Sauces & 0.35 \\
Refined cereals & 0.35 \\
Cured meat & 0.34 \\
Sweets & 0.3 \\
Sugary dairy products & 0.29 \\
Additives & 0.26 \\
Fats & 0.23 \\
\hline
\end{tabular}

Bartlett's test of sphericity $=p<0.001$

Measure of Sample Adequacy (MSA) $=0.78$

Standardized Cronbach's a $=0.67$

$N=4400$

HPF consumer for the item, as shown in the column "Criteria for 1 point" in Table 4. For the self-reported version of the questionnaire, this column should be removed from the questionnaire form since it is intended for the use of the person assessing the score only. Using baseline data from the PREDIMED-Plus FFQ, the percentage of HPF over total grams per day according to the questionnaire items was calculated for each patient. This was used as the dependent variable in a linear regression with the sQ-HPF score obtained for each patient to establish the following equation for the regression line: "HPF consumption (\% g/ day $)=(3.7 \times$ sQ-HPF score $)+7.6$ ". This equation allows the estimation of the HPF consumption from the sQ-HPF score, as shown at the bottom of Table 4 .

Weighted $\mathrm{k}$ coefficients were calculated between HPF consumption tertiles according to the sQ-HPF and the four existing classification systems (Supplementary Table 2). The highest agreement was for the comparison with UNC tertiles $(\kappa=0.88)$, followed by IFIC tertiles $(\kappa=0.65)$ and IARC tertiles $(\kappa=0.50)$. The comparison of tertiles according to the sQ-HPF with NOVA tertiles of HPF showed a fair agreement $(\kappa=0.36)$. These comparisons were in accordance with the corresponding agreement plots (Fig. 2).

\section{Dietary, lifestyle and cardiometabolic characteristics of PREDIMED-Plus participants according to the SQ-HPF score}

We aimed to investigate whether changes in HPF consumption as estimated from the FFQ and the four different systems were also detected when the sQ-HPF was 
Table 4 Screening questionnaire of highly processed food consumption (sQ-HPF)

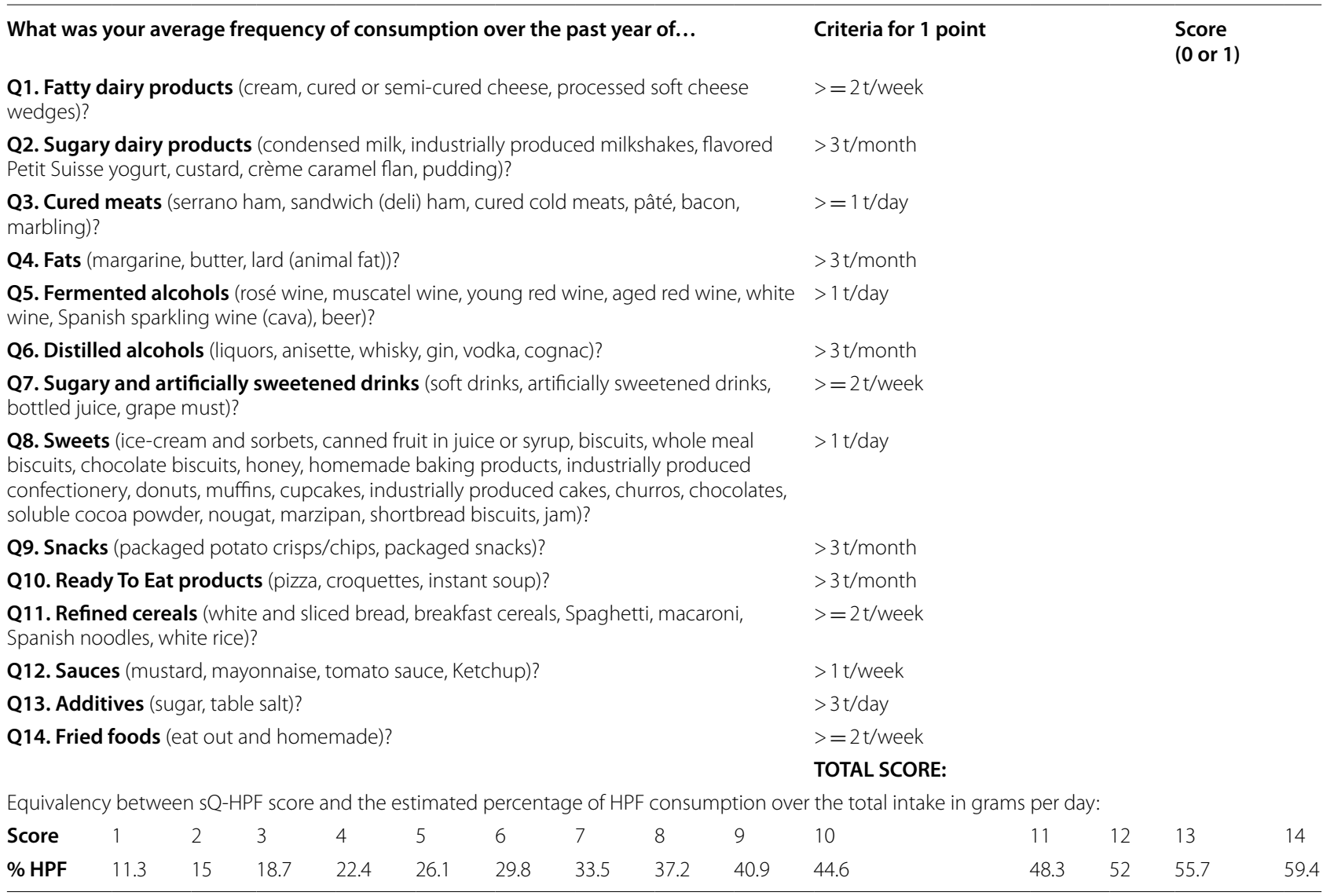

used. In addition, we wanted to analyze the dietary profile across tertiles of the SQ-HPF score, since this is a tool to evaluate a particular dietary pattern. Dietary characteristics of PREDIMED-Plus participants at baseline are shown in Table 5, grouped by HPF consumption tertiles according to the score obtained in the sQ-HPF (T1 lowest score, T3 - highest score). Consumption of food groups included in the questionnaire was the highest for subjects in T3 of the sQ-HPF score, which was not the case for vegetables, fruits, and legumes. Dairy products and fish consumption were not different among tertiles. With all the classification systems, subjects in T3 showed the highest HPF consumption (percentage over total grams per day: $12.45 \pm 8.51$ for NOVA, $54.85 \pm 11.01$ for IARC, $29.26 \pm 12.02$ for IFIC and $30.34 \pm 12.40$ for UNC, $35.05 \pm 12.24$ for questionnaire estimated HPF consumption).

Associations between lifestyle and cardiometabolic parameters and HPF consumption have been previously reported, so we next aimed to analyze if we could detect changes in these variables across tertiles of the sQ-HPF score. Lifestyle and cardiometabolic characteristics of PREDIMED-Plus participants at baseline grouped by
HPF consumption tertiles showed differences according to the sQ-HPF score (Table 6). Participants ranked in the highest tertile had higher levels of triglycerides $(161.05 \pm 90.55 \mathrm{mg} / \mathrm{dL})$, higher weight $(90.68 \pm 13.10 \mathrm{~kg})$ and waist circumference $(109.83 \pm 9.45 \mathrm{~cm})$ compared to those in the lowest tertile. No significant changes among tertiles were detected in fasting glucose and total cholesterol levels. Subjects in T3 of the sQ-HPF score spent more time watching TV than $\mathrm{T} 1$ subjects $(4.05 \pm 2.02 \mathrm{~h} /$ day), while sleeping hours were similar across tertiles. Around half of the subjects classified in T3 were classified as sedentary (51.5\%). Concerning eating habits, $30.5 \%$ of the subjects with the highest sQ-HPF score reported snacking.

\section{Assessing longitudinal changes in HPF consumption with the sQ-HPF}

Longitudinal analysis of HPF consumption estimated from the FFQ by each classification system revealed significant differences across the first 3 years of the PREDIMED-Plus study. In all cases, mean HPF consumption showed a trend towards a decrease that was lower in year 2 than baseline (Table 7). This was also the case when 

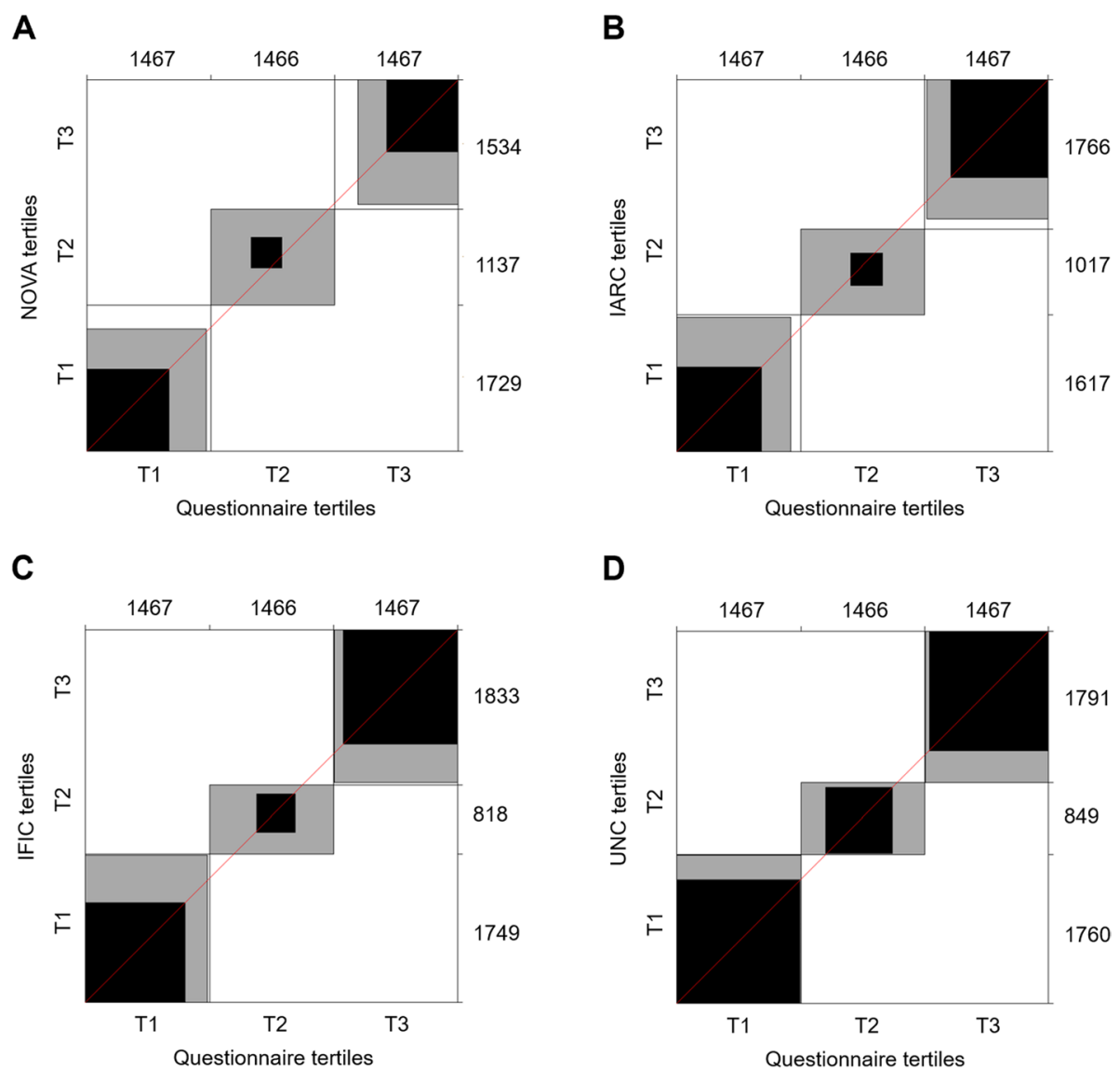

Fig. 2 Agreement plots of tertiles of HPF consumption. Visual representation of contingency tables between the sQ-HPF tertiles and A NOVA HPF tertiles, B IARC HPF tertiles, C IFIC HPF tertiles and D UNC HPF tertiles. Marginal totals of the contingency table are located on the top and right axis. Shading represents the level of agreement, black indicates "perfect agreement", and grey indicates "partial agreement". The extent to which rectangles deviate from the diagonal line of no bias indicates the extent of disagreement, and the position (above/below) indicates direction of the disagreement. HPF: highly processed food

HPF consumption was estimated through the sQ-HPF $(22.9 \pm 0.22 \%$ of $\mathrm{g} /$ day at baseline and $17.3 \pm 0.22 \%$ of $\mathrm{g} /$ day in year 2).

\section{Discussion}

This article presents the sQ-HPF, a short, integrative, and easy-to-use questionnaire to estimate HPF consumption (Table 4). The development process involved a carefully designed statistical analysis and practical considerations for its use in a clinical/epidemiological context. This new tool includes 14 food and beverage items of which the frequency of consumption is recorded, based on a previously validated FFQ from the PREDIMED-Plus Trial [38-40]. Each item is scored as 1 if the frequency of consumption corresponds to the HPF dietary pattern, according to the calculated thresholds, and as 0 otherwise. Therefore, the higher the score, the higher the consumption of HPF. Moreover, this score can be used to estimate the percentage of HPF consumption over total intake, avoiding the need to administer a lengthy FFQ (Table 4) [63].

The present work demonstrates that statistical approaches such as EFA and Cronbach's analysis are valuable tools for developing integrative tools related to dietary patterns and eating habits. Indeed, analysis of questionnaire items through EFA demonstrated that they identified one core construct, the HPF dietary pattern (Table 3) [64]. This was expected considering that items were selected based on a positive association with the variable tertile agreement through binomial logistic regression (Table 1). This resulted in 14 questions based on the frequency of consumption of food groups associated with a higher HPF consumption. One of the reasons for this was that, in this way, the questionnaire could identify people with an HPF dietary pattern with a focus on the frequency of consumption and not on the specific HPF items they consumed, so that the questionnaire could detect different HPF dietary patterns. 
Table 5 Dietetic characteristics of PREDIMED-Plus participants at baseline according to tertiles of the sQ-HPF score

\begin{tabular}{|c|c|c|c|c|}
\hline & \multicolumn{3}{|c|}{ Tertiles of the sQ-HPF score } & \multirow[b]{2}{*}{$p^{1}$} \\
\hline & T1 (lowest) & $\mathrm{T} 2$ & T3 (highest) & \\
\hline $\mathbf{n}$ & 1765 & 1223 & 1412 & \\
\hline sQ-HPF score & $1.99(0.96)$ & $4.49(0.50)$ & $7.49(1.47)$ & $<0.001$ \\
\hline Quest. HPF (\% of g/day) & $13.91(9.13)$ & $25.45(12.73)$ & $35.01(12.24)$ & $<0.001$ \\
\hline NOVA HPF (\% of g/day) & $4.86(5.04)$ & $8.37(7.23)$ & $12.45(8.51)$ & $<0.001$ \\
\hline IARC HPF (\% of g/day) & $38.85(11.36)$ & $47.47(12.34)$ & $54.85(11.01)$ & $<0.001$ \\
\hline IFIC HPF (\% of g/day) & $13.17(8.85)$ & $21.77(12.33)$ & $29.26(12.02)$ & $<0.001$ \\
\hline UNC HPF (\% of g/day) & $11.40(8.82)$ & $21.79(12.83)$ & $30.34(12.40)$ & $<0.001$ \\
\hline Fatty dairy (g/day) & $11.13(13.93)$ & $19.15(21.36)$ & $25.19(20.27)$ & $<0.001$ \\
\hline Sugary dairy (g/day) & $3.47(13.47)$ & $7.09(21.96)$ & $16.46(36.18)$ & $<0.001$ \\
\hline Cured meats (g/day) & $24.20(16.27)$ & $32.75(21.80)$ & $44.62(27.46)$ & $<0.001$ \\
\hline Fats (g/day) & $0.66(2.14)$ & $1.47(3.47)$ & $2.33(4.18)$ & $<0.001$ \\
\hline Fermented alcohol (g/day) & $73.34(149.00)$ & $208.30(298.60)$ & $324.26(342.83)$ & $<0.001$ \\
\hline Distilled alcohol (g/day) & $0.80(4.37)$ & $3.23(11.13)$ & $7.74(17.03)$ & $<0.001$ \\
\hline Sugary drinks (g/day) & $33.95(97.29)$ & $77.08(153.91)$ & $143.91(195.14)$ & $<0.001$ \\
\hline Sweets (g/day) & $32.99(30.54)$ & $53.02(47.10)$ & $65.94(43.71)$ & $<0.001$ \\
\hline Snacks (g/day) & $1.27(3.05)$ & $2.90(5.85)$ & $6.65(10.15)$ & $<0.001$ \\
\hline Ready To Eat (g/day) & $3.81(6.73)$ & $7.18(12.61)$ & $12.99(16.23)$ & $<0.001$ \\
\hline Refined cereals (g/day) & $71.23(65.58)$ & 110.87 (88.72) & $146.36(89.88)$ & $<0.001$ \\
\hline Sauces (g/day) & $1.56(2.12)$ & $2.52(2.77)$ & $4.15(4.42)$ & $<0.001$ \\
\hline Additives (g/day) & $5.04(8.08)$ & $8.53(11.67)$ & $13.45(14.90)$ & $<0.001$ \\
\hline Fried (times/day) & $0.14(0.17)$ & $0.28(0.33)$ & $0.43(0.37)$ & $<0.001$ \\
\hline Vegetables (g/day) & $362.07(148.70)$ & $324.10(142.63)$ & $296.94(131.27)$ & $<0.001$ \\
\hline Fruits (g/day) & $397.36(226.62)$ & $354.80(215.93)$ & $309.72(194.70)$ & $<0.001$ \\
\hline Legumes (g/day) & $21.06(12.03)$ & $21.18(12.41)$ & $20.12(10.04)$ & 0.018 \\
\hline Cereals (g/day) $^{a}$ & $125.72(64.90)$ & $149.96(80.81)$ & $174.99(80.06)$ & $<0.001$ \\
\hline Dairy (g/day) & $342.27(210.61)$ & $337.07(201.45)$ & $346.82(202.03)$ & 0.428 \\
\hline Meat (g/day) & $131.87(53.71)$ & $146.04(56.49)$ & $166.94(61.44)$ & $<0.001$ \\
\hline Fish (g/day) & $103.97(46.74)$ & $101.91(46.44)$ & $101.30(50.20)$ & 0.211 \\
\hline
\end{tabular}

Data shown as "mean (standard deviation, SD)". One-way ANOVA test used for continuous variables. Significant $p$-values (<0.05) shown in bold. HPF consumption was estimated as the percentage over total grams per day, except for fried foods (data not available)

${ }^{1} P$-values adjusted for age, sex, recruitment center, energy intake, physical activity level, medication for blood pressure and diabetes, working status, educational level, and civil status

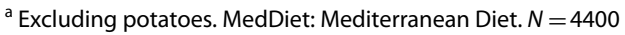

Another reason for the selection of items is that the questionnaire can also provide information on how to intervene to improve health in other populations by identifying the food groups most frequently consumed by the respondent and allowing for customized targeting of the dietary intervention to reduce consumption of those food groups. Finally, this selection was performed to simplify the use and interpretation of the questionnaire. In this way, the questionnaire rapidly results in a score that increases with HPF consumption and can be used to categorize the respondent accordingly. Notably, the questionnaire was designed to encompass criteria from four leading food processing-based classification systems NOVA, IARC, IFIC, and UNC -, so the categorization as
HPF consumer occurs according to at least two of these classification systems (tertile agreement) [20]. This is a key asset of the sQ-HPF, which makes it more comprehensive than other methods that have been proposed and are limited to one classification system [63]. In this regard, the limitations of the NOVA system, the most used classification system, have been widely discussed [65] and it has been shown that the choice of the classification system can have a significant impact on research outcomes [20]. Therefore, the integrative approach used to create the $\mathrm{sQ}-\mathrm{HPF}$ is undoubtedly a critical advantage contributing towards an objective measurement of $\mathrm{HPF}$ consumption and its association to disease. In addition, a reason for choosing food groups rather than specific food 
Table 6 Lifestyle and cardiometabolic characteristics of PREDIMED-Plus participants at baseline according to tertiles of the sQ-HPF score

\begin{tabular}{|c|c|c|c|c|}
\hline & \multicolumn{3}{|c|}{ Tertiles of the sQ-HPF score } & \multirow[b]{2}{*}{$p^{1}$} \\
\hline & T1 (lowest) & $\mathrm{T} 2$ & T3 (highest) & \\
\hline n & 1765 & 1223 & 1412 & \\
\hline Weight (kg) & $83.32(12.31)$ & $87.07(13.07)$ & $90.68(13.10)$ & $<0.001$ \\
\hline Waist circumference $(\mathrm{cm})$ & $105.92(9.66)$ & $107.92(9.61)$ & $109.83(9.45)$ & $<0.001$ \\
\hline BMI $\left(\mathbf{k g} / \mathrm{m}^{2}\right)$ & $32.60(3.50)$ & $32.63(3.43)$ & $32.53(3.38)$ & 0.699 \\
\hline Glucose (mg/dL) & $114.12(29.86)$ & $114.98(29.89)$ & $112.94(29.48)$ & 0.098 \\
\hline Total cholesterol (mg/dL) & $198.59(38.18)$ & $195.77(37.63)$ & 197.35 (38.78) & 0.086 \\
\hline Triglycerides (mg/dL) & $146.33(72.04)$ & $153.74(76.26)$ & $161.05(90.55)$ & $<0.001$ \\
\hline Sleep time (hours/day) & $7.00(1.24)$ & $7.04(1.23)$ & $7.09(1.16)$ & 0.142 \\
\hline TV time (hours/day) & $3.72(1.82)$ & $3.89(1.92)$ & $4.05(2.02)$ & $<0.001$ \\
\hline Sedentariness (\%) & $717(40.6)$ & $549(44.9)$ & $727(51.5)$ & $<0.001$ \\
\hline Binge eating (\%) & $114(6.5)$ & $80(6.5)$ & $119(8.4)$ & 0.066 \\
\hline $\mathbf{N}^{\circ}$ binges/week ${ }^{\mathrm{a}}$ & $2.37(1.73)$ & $2.48(1.83)$ & $2.6(1.81)$ & 0.613 \\
\hline Snacking (\%) & $469(26.6)$ & $326(26.7)$ & $430(30.5)$ & 0.029 \\
\hline
\end{tabular}

Data shown as "mean (standard deviation, SD)" for continuous variables and as "number of subjects (\%)" for categorical variables. One-way ANOVA test used for continuous variables and Chi-squared test used for categorical variables. Significant $p$-values $(<0.05)$ shown in bold

$B M I$ Body Mass Index, PA Physical activity

${ }^{1}$ For continuous variables, $p$-values are adjusted for age, sex, recruitment center, energy intake, physical activity level, medication for blood pressure and diabetes, working status, educational level, and civil status

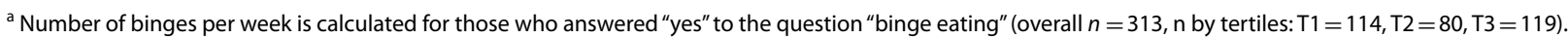
$N=4400$

items was that this would allow assigning specific food items to groups in the questionnaire - even if they were not initially considered because they were not present in the FFQ - attending to similar characteristics than one of the 14 food groups.

Another significant advantage of the sQ-HPF is its quick and easy administration and interpretation,

Table 7 Longitudinal changes in HPF consumption by PREDIMED-Plus participants

\begin{tabular}{|c|c|c|c|c|}
\hline Study timepoint & Baseline & Year 1 & Year 2 & $p$ for trend \\
\hline sQ-HPF score & $4.15(0.04)$ & $3.01(0.04)$ & $3.02(0.04)$ & $<0.0001$ \\
\hline $\begin{array}{l}\text { Quest. HPF (\% of g/ } \\
\text { day) }\end{array}$ & $22.9(0.22)$ & $17.2(0.22)$ & $17.3(0.22)$ & $<0.0001$ \\
\hline $\begin{array}{l}\text { NOVA HPF (\% of g/ } \\
\text { day) }\end{array}$ & $7.98(0.12)$ & $5.45(1.12)$ & $5.45(0.12)$ & $<0.0001$ \\
\hline $\begin{array}{l}\text { IARC HPF (\% of g/ } \\
\text { day) }\end{array}$ & $45.6(0.23)$ & $40.3(0.23)$ & $39.9(0.23)$ & $<0.0001$ \\
\hline IFIC HPF (\% of g/day) & $20.1(0.21)$ & $16.8(0.21)$ & $16.4(0.21)$ & $<0.0001$ \\
\hline UNC HPF (\% of g/day) & $19.5(0.22)$ & $14.7(0.22)$ & $14.8(0.22)$ & $<0.0001$ \\
\hline
\end{tabular}

Data are shown as "adjusted mean (standard error, SE)". Linear mixed model used to assess changes in HPF consumption over time, adjusted for age, sex, recruitment center, energy intake, physical activity level, medication for blood pressure and diabetes, working status, educational level, and civil status. Significant linear trend $p$-values $(<0.05)$ shown in bold. HPF consumption was estimated as the percentage over total grams per day, except for fried foods (data not available). $N=3284$ regardless of the method of administration (i.e., selfreported or interviewer-led). This is particularly useful at the epidemiological level, where a high volume of responses is often collected and the length and subsequent processing of questionnaires is an important aspect of study design [66]. Despite its apparent simplicity, the ability of the sQ-HPF to classify subjects according to their HPF consumption is comparable to other more involved classification systems (Supplementary Table 2). As a reflection of this, longitudinal changes in HPF consumption estimated by the four classification systems were also detected with the same significance by the sQ-HPF estimation (Table 7). Furthermore, significant differences among participants grouped according to $\mathrm{SQ}-\mathrm{HPF}$ scores could be detected in weight, waist circumference, and hours spent watching TV, among others (Table 6). These results indicate the potential of the sQHPF as an initial tool to evaluate the impact of HPF consumption on lifestyle in large-scale intervention trials, such as PREDIMED-Plus. For these reasons, we firmly believe that the consistent use of the SQ-HPF in epidemiological studies could contribute to a robust understanding of the relationship between HPF dietary patterns and health.

The applicability of the sQ-HPF spans not only epidemiological research but also public health and clinical nutrition. The use of "a priori" screening tools to define 
dietary habits and patterns plays an important role in developing personalized nutrition advice [67]. Several epidemiological studies have shown the importance of using dietary patterns to assess the association between dietary exposure and risk of developing chronic diseases [14], giving rise to valuable screening tools aimed at large populations [68]. Most of the developed scores and indices emphasize the importance of healthy dietary habits - Mediterranean diet [41, 69], Nordic diet [70], "healthy" diet [71, 72] - based on a theoretical rationale. However, some studies have reflected the need to capture deleterious eating habits that present a counteractive distortion over the beneficial effects of these diets [67]. In this regard, some approximations focused on the assessment of positive health effects of the diet have included potentially harmful items in their composition, such as the Healthy Eating Index (HEI) [73, 74] and the Alternate HEI (AEHI) [75] to encapsulate the global adequacy to dietary guidelines. The sQ-HPF presented here could thus be a complementary tool that counteracts the analysis from questionnaires aimed at healthy dietary effects. In addition, its simplicity makes it easy to be implemented in the clinical practice, for example, at the level of primary care, for disease-preventing purposes. Furthermore, the sQ-HPF integrates the divergent UPF and HPF definitions through an agglomerative statistical analysis of commonly used criteria, which provides additional consistency to its application.

Regarding public health applications, the limitation of the so-called "discretionary foods" consumption has been gradually incorporated into health policies [76-78]. These foods include confectionery, soft drinks, biscuits, snacks, cakes and pastries, among others [76], most of which are considered HPF [30]. In keeping with this, we propose the use of the $\mathrm{SQ}-\mathrm{HPF}$ as a screening tool to identify trends in consumption of these types of foods in large populations [79], to consistently identify foods that can be targeted in public health campaigns [19]. This will also contribute to harmonizing the methods of assessing government policies addressing the healthiness of food environments, a well-exposed need for the worldwide prevention of diet-related diseases $[11,19,80]$.

One of the main limitations of the ad hoc development of the SQ-HPF is that its reproducibility in other populations is necessary. The PREDIMED-Plus cohort comprises older adults with metabolic syndrome and overweight or obesity and a limited HPF consumption, so the reproducibility of the sQ-HPF in populations with different characteristics will require further validation. Another limitation is that the FFQ used for the initial development of the questionnaire is not specifically designed to measure HPF consumption. However, it contains a considerable number of items categorized as HPF and UPF by current food processing-based classifications [20]. These include industrial biscuits, milkshakes, bakery products, cured meats, RTE preparations, snacks, and soft drinks. Therefore, the sQ-HPF was constructed so that specific HPF are very likely to fall into one of the groups defined in the questionnaire due to their similar description and characteristics to the items already specified in the questionnaire. The use of an FFQ has other limitations, such as recall bias that can impact the accuracy of the data collected [40], but its use to evaluate dietary intake in large epidemiological studies is widely recognized as suitable [39]. We aimed to develop a screener for HPF consumption, so it could be used as a tool that allowed rapid screening of a large population and the identification of consumers with a high HPF dietary profile. For an in-depth study of the specific items that make up the dietary pattern of each consumer, it will still be necessary to use more detailed FFQs or dietary recall interviews. Different research teams have developed FFQs aimed to evaluate dietary intake from HPFs $[81,82]$, so it would be of interest to compare these to the sQ-HPF through intra-class correlation coefficient analyses. In the case of a good correlation, we think that the sQ-HPF would present the advantage of being shorter and more direct regarding the estimation of HPF consumption, which will facilitate the work in epidemiological research and clinical practice.

\section{Conclusions}

The sQ-HPF is an integrative, short, and easy-to-use questionnaire that can be used to screen HPF consumption in large populations for epidemiological or public health purposes. Due to the straightforward score calculation and interpretation, it could aid Personalized Nutrition practice and food policy-makers in the implementation of effective strategies to tackle diet-related disorders associated with HPF consumption.

\section{Abbreviations \\ er-MedDiet: Energy-restricted Mediterranean diet; FFQ: Food frequency questionnaire; HPF: Highly processed food; IARC-EPIC: International Agency for Research on Cancer - European Prospective Investigation into Cancer and Nutrition; IFIC: International Food Information Council; MetS: Metabolic syndrome; NHS: Nurses' Health Study; PA: Physical activity; PREDIMED: from the Spanish "PREvention with MEDiterranean Dlet"; sQ-HPF: Screening question- naire of HPF consumption; UNC: University of North Carolina; UPF: Ultra- processed food.}

\section{Supplementary Information}

The online version contains supplementary material available at https://doi. org/10.1186/s12966-021-01240-6.

Additional file 1.

Additional file 2 


\section{Acknowledgements}

The authors especially thank the PREDIMED-Plus participants for their enthusiastic collaboration, the PREDIMED-Plus personnel for their outstanding support, and the personnel from associated primary health care centers for their exceptional effort. CIBEROBN is an initiative of ISCIII, Spain.

\section{Authors' contributions}

M.A.M.M.-G., J.S.-S., D.C., H.S., J.A.M., A.M.A.-G., J.W., J.V., D.R., J.L.-M., R.E., F.J.T., J.L., L.S.-M., A.B.-C., J.A.T., V.M.S., X.P., J.J.G., P.M.-M., J.V., C.V., E.R., J.B., N.B., P.G.-S. M.D.Z., I.A., J.V.-L., F.J.B.-L, S.G.-P., J.K., A.G.-R., M.R.B.-L., J.M.S.-L., M.B.-R., N.K., C.S., K.A.P.-V., M.A.Z., L.T.-S., Z.V.R., M.A.M. and M.M. contributed to study concept and design, research and data collection and debugging. R.S.-C. designed statistical approach. C.C.-M. conducted bibliographic research. C.M.-P. conducted bibliographic research, data preparation, statistical analysis and wrote initial drafts. L.D., R.S.-C. and J.M.O. revised analytical methods, findings, and manuscript. All authors read and approved the final manuscript.

\section{Funding}

The following funding bodies contributed to study concept and design, research, and data collection for the PREDIMED-Plus study. The PREDIMEDPlus trial was supported by the European Research Council (Advanced Research grant 2014-2019; agreement \#340918; granted to M.A.M-G.); the official Spanish institutions for funding scientific biomedical research, CIBER Fisiopatología de la Obesidad y Nutrición (CIBEROBN) and Instituto de Salud Carlos III (ISCIII) through the Fondo de Investigación para la Salud (FIS) which is co-funded by the European Regional Development Fund (coordinated FIS projects led by J.S-S. and J.V., including the following projects: PI13/00673, Pl13/00492, Pl13/00272, Pl13/01123, Pl13/00462, Pl13/00233, Pl13/02184, Pl13/00728, Pl13/01090, Pl13/01056, Pl14/01722, Pl14/00636, Pl14/00618, PI14/00696, PI14/01206, PI14/01919, PI14/00853, PI14/01374, PI14/00972, PI14/00728, Pl14/01471, Pl16/00473, Pl16/00662, Pl16/01873, Pl16/01094, PI16/00501, PI16/00533, PI16/00381, Pl16/00366, PI16/01522, PI16/01120, Pl17/00764, Pl17/01183, Pl17/00855, Pl17/01347, Pl17/00525, Pl17/01827, Pl17/00532, Pl17/00215, Pl17/01441, Pl17/00508, Pl17/01732, Pl17/00926, Pl19/00957, Pl19/00386, Pl19/00309, Pl19/01032, Pl19/00576, Pl19/00017, PI19/01226, PI19/00781, PI19/01560, PI19/01332), and the Especial Action Project "Implementación y evaluación de una intervención intensiva sobre la actividad física Cohorte PREDIMED-Plus" (J.S-S.); the Recercaixa (grant number 2013ACUP00194) (J.S-S.). Moreover, J.S-S. gratefully acknowledges the financial support by ICREA under the ICREA Academia program; the SEMERGEN grant; Department of Health of the Government of Navarra (61/2015), the Fundació La Marató de TV (Ref. 201630.10); the AstraZeneca Young Investigators Award in Category of Obesity and T2D 2017 (D.R.); grants from the Consejería de Salud de la Junta de Andalucía (PI0458/2013; PS0358/2016; PI0137/2018), the PROMETEO/2017/017 grant from the Generalitat Valenciana, the SEMERGEN grant; grant of support to research groups 35/2011 (Balearic Islands Government; FEDER funds) (J.A.T.). J.K. was financially supported by the Juan de la Cierva-Incorporación research grant (IJC2019-042420-I) of the Spanish Ministry of Economy, Industry and Competitiveness and the European Social Funds. The following funding bodies contributed to data preparation and analysis, bibliographic research, and manuscript writing. The METHYL-UP project was supported by the Spanish Ministry of Science and Innovation (RTI2018-095569-B-I00, Programa de Proyectos Orientados a los Retos de la Sociedad "Projects Toward Society Challenges Program"). R.S.-C. acknowledges financial support from the Juan de la Cierva Program Training Grants of the Spanish State Research Agency of the Spanish Ministerio de Ciencia e Innovación y Ministerio de Universidades (FJC2018-038168- I). C.M.-P. was financially supported by a joint grant from the Community of Madrid and the European Social Fund (PEJD-2019-POST/SAL-15892). C. C.-M. was financially supported by the Formación de Personal Investigador (FPI) grant from the Spanish Ministerio de Ciencia, Innovación y Universidades (PRE2019-087643).

\section{Availability of data and materials}

There are restrictions on data availability for the PREDIMED-Plus trial due to the signed consent agreements around data sharing, which only allow access to external researchers for studies following the project purposes. Requestors wishing to access the PREDIMED-Plus trial data used in this study can make a request to the PREDIMED-Plus trial Steering Committee chair: jordi.salas@urv. cat. The request will then be passed to members of the PREDIMED-Plus Steering Committee for deliberation.

\section{Declarations}

\section{Ethics approval and consent to participate}

The study protocol, including study design and data collection, can be found at the PREDIMED-Plus website (https://www.predimedplus.com/en/) and was approved according to the ethical standards of the Declaration of Helsinki by the Institutional Review Boards (IRBs) of all participating centers. All participants provided written consent of their participation in the study.

\section{Consent for publication}

Not applicable.

\section{Competing interests}

J.S-S reports grants from CIBEROBN, ISCIII (Spain), during the conduct of the study; non-financial support from Nut and Dried Fruit Foundation, personal fees from Instituto Danone Spain, other from Danone S.A., other from Font Vella Lanjaron, personal fees and grants from Eroski Distributors, grants from Nut and Dried Fruit Foundation, grants from Eroski Distributors, personal fees from Nut and Dried Fruit Foundation, outside the submitted work. E.R reports grants, personal fees, non-financial support and other from California Walnut Commission, grants, personal fees, non-financial support and other from Alexion, personal fees, non-financial support and other from Ferrer International, personal fees from Amarin, personal fees, non-financial support and other from Danone, outside the submitted work. J. L-M reports personal fees and non-financial support from AMGEN, personal fees and non-financial support from SANOFI, personal fees from MSD, personal fees from Laboratorios Dr. Esteve, personal fees from NOVO-NORDISK outside the submitted work.

\section{Author details}

${ }^{1}$ Nutritional Genomics and Epigenomics Group, Precision Nutrition and Obesity Program, IMDEA Food, CEI UAM + CSIC, Ctra. Cantoblanco, 8, 28049 Madrid, Spain. ${ }^{2}$ Biomedical Research Centre for Obesity Physiopathology and Nutrition Network (CIBEROBN), Instituto de Salud Carlos III (ISCIII), 28029 Madrid, Spain. ${ }^{3}$ Department of Preventive Medicine and Public Health, University of Navarra, IdiSNA, 31009 Pamplona, Spain. ${ }^{4}$ Department of Nutrition, Harvard T. H. Chan School of Public Health, Boston, MA 02115, USA. ${ }^{5}$ Unitat de Nutrició Humana, Departament de Bioquímica i biotecnologia, Universitat Rovira i Virgili, 43201 Reus, Spain. ${ }^{6}$ Human Nutrition Unit, Institut d'Investigació Sanitària Pere Virgili (IISPV), 43204 Reus, Spain. ${ }^{7}$ Department of Preventive Medicine, University of Valencia, 46010 Valencia, Spain. ${ }^{8}$ Cardiovascular Risk and Nutrition Research Group (CARIN), Hospital del Mar Medical Research Institute (IMIM), 08003 Barcelona, Spain. ${ }^{9}$ Cardiometabolic Nutrition Group, IMDEA Food, CEI UAM + CSIC, 28049 Madrid, Spain. ${ }^{10}$ Department of Nutrition, Food Sciences and Physiology, University of Navarra, 31009 Pamplona, Spain. ${ }^{11}$ Bioaraba Health Research Institute, Osakidetza Basque Health Service, Araba University Hospital, University of the Basque Country UPV/ EHU, 01009 Vitoria-Gasteiz, Spain. ${ }^{12}$ Department of Nursing, School of Health Sciences, University of Málaga, Instituto de Investigación Biomédica de Málaga (IBIMA), 29016 Málaga, Spain. ${ }^{13}$ Centro de Investigación Biomédica en Red de Epidemiología y Salud Pública (CIBERESP), Instituto de Salud Carlos III, 28029 Madrid, Spain. ${ }^{14}$ Instituto de Investigación Sanitaria y Biomédica de Alicante (ISABIAL-UMH), 03010 Alicante, Spain. ${ }^{15}$ Research Group on Nutritional Epidemiology \& Cardiovascular Physiopathology (NUTRECOR), Health Research Institute of the Balearic Islands (IdISBa), University Hospital Son Espases (HUSE), 07120 Palma de Mallorca, Spain. ${ }^{16}$ Lipids and Atherosclerosis Unit, Department of Internal Medicine, Maimonides Biomedical Research Institute of Cordoba (IMIBIC), Reina Sofia University Hospital, University of Cordoba, 14017 Córdoba, Spain. ${ }^{17}$ Department of Internal Medicine, IDIBAPS, Hospital Clinic, University of Barcelona, 08007 Barcelona, Spain. ${ }^{18}$ Department of Endocrinology, Instituto de Investigación Biomédica de Málaga (IBIMA), Virgen de la Victoria Hospital, University of Málaga, 29016 Málaga, Spain. ${ }^{19}$ Department of Family Medicine, Research Unit, Distrito Sanitario Atención Primaria Sevilla, 41013 Sevilla, Spain. ${ }^{20}$ Research Institute of Biomedical and Health Sciences (IUIBS), University of Las Palmas de Gran Canaria, Preventive Medicine Service, Centro Hospitalario Universitario Insular Materno Infantil (CHUIMI), Canarian Health Service, 35016 Las Palmas, Spain. ${ }^{21}$ Department of Preventive Medicine and Public Health, University of Granada, 18011 Granada, Spain. ${ }^{22}$ Research Group on Community Nutrition \& Oxidative Stress, University of Balearic Islands-IUNICS \& IDISBA, 07122 Palma de Mallorca, Spain. ${ }^{23}$ Institute of Biomedicine (IBIOMED), University of León, 24071 León, Spain. 
${ }^{24}$ Lipids and Vascular Risk Unit, Internal Medicine, Hospital Universitario de Bellvitge, Hospitalet de Llobregat, 08907 Barcelona, Spain. ${ }^{25}$ Departamento de Ciencias de la Salud, Centro de Estudios Avanzados en Olivar y Aceites de Oliva, Universidad de Jaén, 23071 Jaén, Spain. ${ }^{26}$ Department of Endocrinology and Nutrition, Instituto de Investigación Sanitaria Hospital Clínico San Carlos (IdISSC), 28040 Madrid, Spain. ${ }^{27}$ Biomedical Research Centre for Diabetes and Metabolic Diseases Network (CIBERDEM), Instituto de Salud Carlos III (ISCIII), 28029 Madrid, Spain. ${ }^{28}$ Endocrinology and Nutrition Service, IDIBAPS, Hospital Clinic, University of Barcelona, 08007 Barcelona, Spain. ${ }^{29}$ Department of Endocrinology and Nutrition, Hospital Fundación Jimenez Díaz, Instituto de Investigaciones Biomédicas IISFJD, University Autónoma, 28015 Madrid, Spain. ${ }^{30}$ Department of Endocrinology and Nutrition, Complejo Hospitalario de Navarra, 31008 Pamplona, Spain. ${ }^{31}$ School of Health Sciences, BlanquernaRamon Llull University, 08001 Barcelona, Spain. ${ }^{32}$ Department of Public Health, University of Málaga, Instituto de Investigación Biomédica de Málaga (IBIMA), 29016 Málaga, Spain. ${ }^{33}$ Internal Medicine Department, Regional University Hospital of Málaga, Instituto de Investigación Biomédica de Málaga (IBIMA), 29010 Málaga, Spain. ${ }^{34}$ Nutrition and Genomics Laboratory, JM USDA Human Nutrition Research Center on Aging, Tufts University, Boston, MA 02155, USA.

Received: 22 July 2021 Accepted: 14 December 2021

Published online: 24 January 2022

\section{References}

1. Baker P, Machado P, Santos T, Sievert K, Backholer K, Hadjikakou M, et al. Ultra-processed foods and the nutrition transition: global, regional and national trends, food systems transformations and political economy drivers. Obes Rev. 2020;21(12) [cited 2021 May 11]. Available from: https:// pubmed.ncbi.nlm.nih.gov/32761763/.

2. Baraldi LG, Martinez Steele E, Canella DS, Monteiro CA. Consumption of ultra-processed foods and associated sociodemographic factors in the USA between 2007 and 2012: evidence from a nationally representative cross-sectional study. BMJ Open. 2018;8(e020574):1-9 [cited 2020 Aug 3]. Available from: http://bmjopen.bmj.com/.

3. Cediel G, Reyes M, Da Costa Louzada ML, Martinez Steele E, Monteiro CA, Corvalán C, et al. Ultra-processed foods and added sugars in the Chilean diet (2010). Public Health Nutr. 2018;21(1):125-33 [cited 2020 Aug 3]. Available from: https://pubmed.ncbi.nlm.nih.gov/28625223/.

4. da Louzada MLC, Martins APB, Canella DS, Baraldi LG, Levy RB, Claro RM, et al. Ultra-processed foods and the nutritional dietary profile in Brazil. Rev Saude Publica. 2015;49(38):1-11 [cited 2020 Aug 3]. Available from: www.scielo.br/rsp.

5. Julia C, Martinez L, Allès B, Touvier M, Hercberg S, Méjean C, et al. Contribution of ultra-processed foods in the diet of adults from the French NutriNet-Santé study. Public Health Nutr. 2018;21(1):27-37 [cited 2020 Aug 3]. Available from: https://www.revistas.usp.br/rsp/article/view/ 189620. https://doi.org/10.11606/s1518-8787.2021055002473.

6. Moubarac J-CC, Batal M, Martins APB, Claro R, Levy RB, Cannon G, et al. Processed and ultra-processed food products: consumption trends in Canada from 1938 to 2011. Can J Diet Pract Res. 2014;75(1):15-21 [cited 2020 Aug 3]. Available from: https://dcjournal.ca/doi/10.3148/75.1.2014 15.

7. Slimani N, Deharveng G, Southgate DAT, Biessy C, Chajès V, van Bakel $M M E$, et al. Contribution of highly industrially processed foods to the nutrient intakes and patterns of middle-aged populations in the European Prospective Investigation into Cancer and Nutrition study. Eur J Clin Nutr. 2009;63(4):S206-25 [cited 2020 Jun 22]. Available from: https:// www.nature.com/articles/ejcn200982.

8. Latasa P, Louzada MLDC, Martinez Steele E, Monteiro CA. Added sugars and ultra-processed foods in Spanish households (1990-2010). Eur J Clin Nutr. 2018;72(10):1404-12 [cited 2020 Aug 3]. Available from: https:// www.nature.com/articles/s41430-017-0039-0.

9. Blanco-Rojo R, Sandoval-Insausti H, López-Garcia E, Graciani A, Ordovás $J M$, Banegas JR, et al. Consumption of ultra-processed foods and mortality: a national prospective cohort in Spain. Mayo Clin Proc. 2019;94(11):2178-88 [cited 2020 Apr 14]. Available from: https://doi.org/ 10.1016/j.mayocp.2019.03.035.

10. Juul F, Hemmingsson E. Trends in consumption of ultra-processed foods and obesity in Sweden between 1960 and 2010. Public Health
Nutr. 2015;18(17):3096-107 [cited 2020 Aug 12]. Available from: https:// pubmed.ncbi.nlm.nih.gov/25804833/.

11. Gibney MJ. Ultra-processed foods: definitions and policy issues. Curr Dev Nutr. 2018;3(2) [cited 2021 May 11]. Available from: https://academic.oup. $\mathrm{com} / \mathrm{cdn} /$.

12. Monteiro CA, Cannon G, Moubarac J-C, Bertazzi Levy R, Laura Louzada MC, Constante JP. The UN decade of nutrition, the NOVA food classification and the trouble with ultra-processing. Public Health Nutr. 2018;21(1):5-17.

13. Monteiro CA, Cannon G, Lawrence M, da Louzada MLC, Pereira Machado P. Ultra-processed foods, diet quality, and health using the NOVA classification system. FAO. 2019. Food and Agriculture Organization of the United Nations (FAO) Headquarters: Viale delle Terme di Caracalla 00153 Rome, Italy. https://www.fao.org/fsnforum/resources/fsn-resources/ultraprocessed-foods-diet-quality-and-health-using-nova-classification.

14. Chen X, Zhang Z, Yang H, Qiu P, Wang H, Wang F, et al. Consumption of ultra-processed foods and health outcomes: a systematic review of epidemiological studies. Nutr J. 2020;19(86):1-10 [cited 2021 Mar 1]. Available from: https://doi.org/10.1186/s12937-020-00604-1.

15. Srour B, Fezeu LK, Kesse-Guyot E, Allès B, Méjean C, Andrianasolo RM, et al. Ultra-processed food intake and risk of cardiovascular disease: prospective cohort study (NutriNet-Santé). BMJ. 2019;365(II1451):1-13.

16. Smaira Fl, Mazzolani BC, Peçanha T, dos Santos KM, Rezende DAN, Araujo $\mathrm{ME}$, et al. Ultra-processed food consumption associates with higher cardiovascular risk in rheumatoid arthritis. Clin Rheumatol. 2020;39(5):1423-8 [cited 2020 Aug 12]. Available from: https://pubmed.ncbi.nlm.nih.gov/ 31902026/.

17. Schnabel L, Kesse-Guyot E, Allès B, Touvier M, Srour B, Hercberg S, et al. Association between ultraprocessed food consumption and risk of mortality among middle-aged adults in France. JAMA Intern Med. 2019;179(4):490-8.

18. da Louzada MLC, Baraldi LG, Steele EM, Martins APB, Canella DS, Moubarac JC, et al. Consumption of ultra-processed foods and obesity in Brazilian adolescents and adults. Prev Med (Baltim). 2015;81:9-15 Available from: https://doi.org/10.1016/j.ypmed.2015.07.018.

19. Popkin BM, Barquera S, Corvalan C, Hofman KJ, Monteiro C, Ng SW, et al. Towards unified and impactful policies to reduce ultra-processed food consumption and promote healthier eating. Lancet Diabetes Endocrinol. 2021; [cited 2021 Apr 19]. Available from: https://linkinghub.elsevier.com/ retrieve/pii/S2213858721000784.

20. Martinez-Perez C, San-Cristobal R, Guallar-Castillon P, Martínez-González MÁ, Salas-Salvadó J, Corella D, et al. Use of different food classification systems to assess the association between ultra-processed food consumption and cardiometabolic health in an elderly population with metabolic syndrome (PREDIMED-plus cohort). Nutrients. 2021;13(7):2471 [cited 2021 Jul 26]. Available from: https://www.mdpi.com/2072-6643/ 13/7/2471/htm.

21. Crino M, Barakat T, Trevena H, Neal B. Systematic review and comparison of classification frameworks describing the degree of food processing. Nutr Food Technol. 2017;3(1):1-12. [cited 2020 Aug 3]. Available from: https://doi.org/10.16966/2470-6086.138.

22. Juul F, Vaidean G, Lin Y, Deierlein AL, Parekh N. Ultra-processed foods and incident cardiovascular disease in the Framingham offspring study. J Am Coll Cardiol. 2021;77(12):1520-31 [cited 2021 Apr 6]. Available from: https://pubmed.ncbi.nlm.nih.gov/33766258/.

23. Canella DS, Levy RB, Martins APB, Claro RM, Moubarac J-CC, Baraldi LG, et al. Ultra-processed food products and obesity in Brazilian households (2008-2009). Votruba SB, editor. PLoS One. 2014;9(3):e92752 [cited 2020 Aug 3]. Available from: https://pubmed.ncbi.nlm.nih.gov/24667658/.

24. de Mendonça RD, Lopes ACS, Pimenta AM, Gea A, Martinez-Gonzalez MA, Bes-Rastrollo M. Ultra-processed food consumption and the incidence of hypertension in a Mediterranean cohort: the Seguimiento Universidad de Navarra project. Am J Hypertens. 2017;30(4):358-66 [cited 2020 Aug 3]. Available from: https://academic.oup.com/ajh/article-abstract/30/4/358/ 2645510.

25. de Mendonça RD, Pimenta AM, Gea A, de la Fuente-Arrillaga C, MartinezGonzalez MA, Lopes ACS, et al. Ultraprocessed food consumption and risk of overweight and obesity: the University of Navarra Follow-Up (SUN) cohort study. Am J Clin Nutr. 2016;104(5):1433-40 [cited 2020 Aug 3]. Available from: https://academic.oup.com/ajcn/article/104/5/1433/45643 89. 
26. Fiolet T, Srour B, Sellem L, Kesse-Guyot E, Allès B, Méjean C, et al. Consumption of ultra-processed foods and cancer risk: results from NutriNet-Santé prospective cohort. BMJ. 2018;360:322. [cited 2020 Aug 3]. Available from: https://doi.org/10.1136/bmj.k322.

27. Schnabel L, Buscail C, Sabate JM, Bouchoucha M, Kesse-Guyot E, Allès $B$, et al. Association between ultra-processed food consumption and functional gastrointestinal disorders: results from the French NutriNetSanté Cohort. Am J Gastroenterol. 2018;113(8):1217-28 [cited 2020 Aug 12]. Available from: https://pubmed.ncbi.nlm.nih.gov/29904158/.

28. Fardet A, Rock E, Bassama J, Bohuon P, Prabhasankar P, Monteiro C, et al. Current food classifications in epidemiological studies do not enable solid nutritional recommendations for preventing diet-related chronic diseases: the impact of food processing. Adv Nutr. 2015;6(6):629-38.

29. Tavares LF, Fonseca SC, Rosa MLG, Yokoo EM. Relationship between ultraprocessed foods and metabolic syndrome in adolescents from a Brazilian Family Doctor Program. Public Health Nutr. 2012;15(1):82-7 [cited 2021 Nov 2]. Available from: https://pubmed.ncbi.nlm.nih.gov/21752314/.

30. Machado PP, Steele EM, Levy RB, Sui Z, Rangan A, Woods J, et al. Ultraprocessed foods and recommended intake levels of nutrients linked to non-communicable diseases in Australia: evidence from a nationally representative cross-sectional study. BMJ Open. 2019;9(e029544) [cited 2021 May 11]. Available from: http://bmjopen.bmj.com/.

31. Alberti KGMM, Eckel RH, Grundy SM, Zimmet PZ, Cleeman Jl, Donato KA, et al. Harmonizing the metabolic syndrome. Circulation. 2009;120(16):1640-5.

32. Martínez-González MA, Buil-Cosiales P, Corella D, Bulló M, Fitó M, Vioque $J$, et al. Cohort profile: design and methods of the PREDIMED-Plus randomized trial. Int J Epidemiol. 2019;48(2):387-8 [cited 2020 Jul 28]. Available from: https://academic.oup.com/ije/article-abstract/48/2/387/ 5202210.

33. Lachat C, Hawwash D, Ocké MC, Berg C, Forsum E, Hörnell A, et al. Strengthening the reporting of observational studies in epidemiologynutritional epidemiology (STROBE-nut): an extension of the STROBE statement. PLoS Med. 2016;13(6):e1002036 [cited 2021 May 31]. Available from: https://journals.plos.org/plosmedicine/article?id=10.1371/journal. pmed.1002036

34. Molina L, Sarmiento M, Peñafiel J, Donaire D, Garcia-Aymerich J, Gomez $M$, et al. Validation of the Regicor short physical activity questionnaire for the adult population. PLoS One. 2017;12(1):168148 [cited 2021 Jun 14]. Available from: www.isciii.es.

35. Topolski TD, LoGerfo J, Patrick DL, Williams B, Walwick J, Patrick MB. The rapid assessment of physical activity (RAPA) among older adults. Prev Chronic Dis. 2006;3(4):1-8

36. Martínez-González MA, López-Fontana C, Varo JJ, Sánchez-Villegas A, Martinez JA. Validation of the Spanish version of the physical activity questionnaire used in the nurses' health study and the health professionals' follow-up study. Public Health Nutr. 2005;8(7):920-7 [cited 2021 Mar 22]. Available from: https://pubmed.ncbi.nlm.nih.gov/16277809/.

37. Wallston KA, Wallston BS, DeVellis R. Development of the multidimensional health locus of control (MHLC) scales. Health Educ Monogr. 1978;6:160-70 Available from: https://nursing.vanderbilt.edu/projects/ wallstonk/pdf/A16.pdf.

38. Martin-Moreno JM, Boyle P, Gorgojo L, Maisonneuve P, Fernandez-rodriguez JC, Salvini S, et al. Development and validation of a food frequency questionnaire in Spain. Int J Epidemiol. 1993;22(3):512-9 [cited 2020 Aug 19]. Available from: https://academic.oup.com/ije/article/22/3/512/ 674681.

39. Fernández-Ballart JD, Lluís Piñol J, Zazpe I, Corella D, Carrasco P, Toledo E, et al. Relative validity of a semi-quantitative food-frequency questionnaire in an elderly Mediterranean population of Spain. Br J Nutr. 2010;103:1808-16 [cited 2020 Aug 19]. Available from: https://doi.org/10. 1017/S0007114509993837.

40. De La Fuente-Arrillaga C, Vá Zquez Ruiz Z, Bes-Rastrollo M, Sampson L, Martinez-González MA. Reproducibility of an FFQ validated in Spain. Public Health Nutr. 2009;13(9):1364-72.

41. Galilea-Zabalza I, Buil-Cosiales P, Salas-Salvadó J, Toledo E, OrtegaAzorín C, Díez-Espino J, et al. Mediterranean diet and quality of life: baseline cross-sectional analysis of the PREDIMED-PLUS trial. PLoS One. 2018;13(6):1-18 [cited 2020 Aug 7]. Available from: https://doi.org/10. 1371/journal.pone.0198974.
42. Schröder H, Zomeño MD, Martínez-González MA, Salas-Salvadó J, Corella $D$, Vioque J, et al. Validity of the energy-restricted Mediterranean Diet Adherence Screener. Clin Nutr. 2021; [cited 2021 Jul 13]. Available from: https://linkinghub.elsevier.com/retrieve/pii/S0261561421003265.

43. Monteiro CA, Levy RB, Claro RM, De Castro IRR, Cannon G. Increasing consumption of ultra-processed foods and likely impact on human health: evidence from Brazil. Public Health Nutr. 2011;14(1):5-13.

44. Monteiro CA, Cannon G, Levy R, Moubarac J-C, Jaime P, Martins AP, et al. NOVA. The star shines bright (Food classification. Public health). World Nutr. 2016;7(1-3):28-38 Available from: https://worldnutritionjournal.org/ index.php/wn/article/view/5.

45. Chajès V, Biessy C, Byrnes $G$, Deharveng G, Saadatian-Elahi M, Jenab $M$, et al. Ecological-Level associations between highly processed food intakes and plasma phospholipid elaidic acid concentrations: results from a cross-sectional study within the European prospective investigation into Cancer and nutrition (EPIC). Nutr Cancer. 2011;63(8):1235-50 [cited $2020 \mathrm{Jul}$ 27]. Available from: https://www.tandfonline.com/doi/abs/10. 1080/01635581.2011.617530.

46. Eicher-Miller HA, Fulgoni lii VL, Keast DR. Processed food contributions to energy and nutrient intake differ among US children by race/ethnicity. Nutrients. 2015;7(12):10076-88 [cited 2020 Jun 23]. Available from: www. mdpi.com/journal/nutrients.

47. Eicher-Miller HA, Fulgoni VL, Keast DR. Contributions of processed foods to dietary intake in the US from 2003-2008: a report of the food and nutrition science solutions joint task force of the Academy of Nutrition and Dietetics, American Society for Nutrition, Institute of Food Technologists. J Nutr. 2012;142(11):2065S-72S [cited 2020 Jun 23]. Available from: / pmc/articles/PMC3593301/?report=abstract.

48. Poti JM, Mendez MA, Ng SW, Popkin BM. Is the degree of food processing and convenience linked with the nutritional quality of foods purchased by US households? Am J Clin Nutr. 2015;101(6):1251-62 [cited 2020 Jun 23]. Available from: https://pubmed.ncbi.nlm.nih.gov/25948666/.

49. R Core Team. R: A language and environment for statistical computing. Vienna: R Foundation for Statistical Computing; 2020. Available from: https://www.r-project.org/

50. RStudio Team. RStudio: integrated development environment for $\mathrm{R}$. Boston: RStudio, Inc; 2018. Available from: http://www.rstudio.com/

51. Signorell A et mult. all. DescTools: tools for descriptive statistics. R package version 0.99.37. 2020. Available from: https://cran.r-project.org/packa ge $=$ DescTools

52. Revelle W. psych: procedures for personality and psychological research. R package version 2.0.7. Evanston: Northwestern University; 2020. Available from: https://cran.r-project.org/package=psych

53. Yoshida K, Bartel A. tableone: create "Table 1" to describe baseline characteristics with or without propensity score weights. R package version 0.12.0. 2020. Available from: https://cran.r-project.org/package=table one.

54. Thiele C. cutpointr: determine and evaluate optimal cutpoints in binary classification tasks. R package version 1.0.32. 2020. Available from: https:// cran.r-project.org/package=cutpointr\%0A.

55. Wei T, Simko V. R package "corrplot": visualization of a correlation matrix (version 0.84). 2017. Available from: https://github.com/taiyun/corrplot.

56. Meyer D, Zeileis A, Hornik K. vcd: visualizing categorical data. R package version 1.4-8. 2020. Available from: https://www.jstatsoft.org/v17/i03/.

57. Kassambara A. rstatix: pipe-friendly framework for basic statistical tests. $R$ package version 0.7.0. 2021. https://CRAN.R-project.org/package=rstatix.

58. Youden WJ. Index for rating diagnostic tests. Cancer. 1950;3(1):32-5 [cited 2021 Mar 23]. Available from: https://pubmed.ncbi.nlm.nih.gov/15405 679/.

59. Kaiser HF. A second generation little jiffy. Psychometrika. 1970;35(4):40115 [cited 2021 Feb 22]. Available from: https://link.springer.com/article/ 10.1007/BF02291817.

60. Bartlett M. A note on the multiplying factors for various chi square approximations. J R Stat Soc Ser B Methodol. 1654;16:296-8 [cited 2021 Feb 22]. Available from: https://www.scienceopen.com/document?vid= 124c659a-1a2b-44cf-8a06-a502d6425a27.

61. Kaiser HF. The application of electronic computers to factor analysis. Educ Psychol Meas. 1960;20(1):141-51 [cited 2021 Mar 17]. Available from: http://journals.sagepub.com/doi/10.1177/001316446002000116. 
62. Cronbach LJ. Coefficient alpha and the internal structure of tests. Psychometrika. 1951;16(3):297-334 [cited 2021 Feb 22]. Available from: https:// link.springer.com/article/10.1007/BF02310555.

63. Fangupo LJ, Haszard JJ, Leong C, Heath ALM, Fleming EA, Taylor RW. Relative validity and reproducibility of a food frequency questionnaire to assess energy intake from minimally processed and ultra-processed foods in young children. Nutrients. 2019;11(6):1-13.

64. Koslowsky M, Scheinberg Z, Bleich A, Mark M, Apter A, Danon Y, et al. The factor structure and criterion validity of the short form of the eating attitudes test. J Pers Assess. 1992;58(1):27-35 [cited 2021 May 14]. Available from: https://www.tandfonline.com/doi/abs/10.1207/s15327752j pa5801_3.

65. Gibney MJ, Forde CG, Mullally D, Gibney ER. Ultra-processed foods in human health: a critical appraisal. Am J Clin Nutr. 2017;106(3):717-24 [cited 2020 Jun 25]. Available from: http://ajcn.nutrition.org/lookup/doi/ 10.3945/ajen.117.160440.

66. Nieuwenhuijsen MJ. Design of exposure questionnaires for epidemiological studies. Occup Environ Med. 2005;62(4):272-80 [cited 2021 May 11]. Available from: http://oem.bmj.com/.

67. San-Cristobal R, Navas-Carretero S, Celis-Morales C, Brennan L, Walsh M, Lovegrove JA, et al. Analysis of dietary pattern impact on weight status for personalised nutrition through on-line advice: the food4Me Spanish cohort. Nutrients. 2015;7(11):9523-37.

68. San-Cristobal R, Navas-Carretero S, Celis-Morales C, Livingstone KM, Stewart-Knox B, Rankin A, et al. Capturing health and eating status through a nutritional perception screening questionnaire (NPSQ9) in a randomised internet-based personalised nutrition intervention: the Food4Me study. Int J Behav Nutr Phys Act. 2017;14(1):1-12.

69. Trichopoulou A, Costacou T, Bamia C, Trichopoulos D. Adherence to a Mediterranean diet and survival in a Greek population. N Engl J Med. 2003;348(26):2599-608 [cited 2021 May 10]. Available from: https:// pubmed.ncbi.nlm.nih.gov/12826634/.

70. Tertsunen H-M, Hantunen S, Tuomainen T-P, Virtanen JK. Adherence to a healthy Nordic diet and risk of type 2 diabetes among men: the Kuopio Ischaemic heart disease risk factor study. Eur J Nutr. 2021; [cited 2021 May 10];Online pub. Available from: https://link.springer.com/10.1007/ s00394-021-02569-1.

71. Toh DWK, Xia X, Sutanto CN, Low JHM, Poh KK, Wang J-W, et al. Enhancing the cardiovascular protective effects of a healthy dietary pattern with wolfberry (Lycium barbarum): a randomized controlled trial. Am J Clin Nutr. 2021; [cited 2021 May 10];Online ahe. Available from: https://acade mic.oup.com/ajcn/advance-article/doi/10.1093/ajcn/nqab062/6272607.

72. Paterson EN, Neville CE, Wallace SM, Woodside JV, Kee F, Young IS, et al. Dietary patterns associated with renal impairment in the Northern Ireland cohort for the longitudinal study of ageing (NICOLA). Eur J Nutr. 2021; [cited 2021 May 10];Published. Available from: https://link.springer. com/10.1007/s00394-021-02579-z.

73. Guenther PM, Kirkpatrick SI, Reedy J, Krebs-Smith SM, Buckman DW, Dodd KW, et al. The healthy eating Index-2010 is a valid and reliable measure of diet quality according to the 2010 dietary guidelines for Americans 1-3. J Nutr Methodol Math Model J Nutr. 2014;144:399-407 [cited 2021 May 10]. Available from: http://jn.nutrition.org.

74. Krebs-Smith SM, Pannucci TRE, Subar AF, Kirkpatrick SI, Lerman JL, Tooze JA, et al. Update of the healthy eating index: HEl-2015. J Acad Nutr Diet. 2018;118(9):1591-602 [cited 2021 May 14]. Available from: https://pubmed.ncbi.nlm.nih.gov/30146071/.

75. McCullough ML, Willett WC. Evaluating adherence to recommended diets in adults: the Alternate Healthy Eating Index. Public Health Nutr. 2006;9(1 A):152-7 [cited 2021 May 14]. Available from: https://pubmed. ncbi.nlm.nih.gov/16512963/.

76. Food Standards Scotland. Briefing paper on discretionary foods. 2018

77. National Health and Medical Research Council. Australian dietary guidelines. Canberra; 2013. [cited 2021 May 10]. Available from: http://www. nhmrc.gov.au

78. Grieger JA, Wycherley TP, Johnson BJ, Golley RK. Discrete strategies to reduce intake of discretionary food choices: a scoping review. Int J Behav Nutr Phys Act. 2016;13(1):1-22 [cited 2021 May 10]. Available from: https://ijbnpa.biomedcentral.com/articles/10.1186/s12966-016-0380-z.

79. Livingstone KM, Celis-Morales C, Navas-Carretero S, San-Cristobal R, Forster $\mathrm{H}$, Woolhead $\mathrm{C}$, et al. Personalised nutrition advice reduces intake of discretionary foods and beverages: findings from the Food4Me randomised controlled trial. Int J Behav Nutr Phys Act. 2021;18(1):70 [cited 2021 Jun 8]. Available from: https://ijbnpa.biomedcentral.com/articles/ 10.1186/s12966-021-01136-5.

80. Phulkerd S, Lawrence M, Vandevijvere S, Sacks G, Worsley A, Tangcharoensathien $\mathrm{V}$. A review of methods and tools to assess the implementation of government policies to create healthy food environments for preventing obesity and diet-related non-communicable diseases. Implement Sci. 2016;11(15) [cited 2021 May 11]. Available from: https://pubmed.ncbi. nlm.nih.gov/26846789/.

81. Sarbagili-Shabat C, Zelber-Sagi S, Fliss Isakov N, Ron Y, Hirsch A, Maharshak N. Development and validation of processed foods questionnaire (PFQ) in adult inflammatory bowel diseases patients. Eur J Clin Nutr. 2020;74(12):1653-60 Available from: https://doi.org/10.1038/ s41430-020-0632-5.

82. Motta VW de L, Lima SCVC, Marchioni DML, Lyra C de O. Food frequency questionnaire for adults in the Brazilian northeast region: emphasis on the level of food processing. Rev Saude Publica 2021;55(51). [cited 2021 Aug 24]. Available from: https://www.revistas.usp.br/rsp/article/view/ 189620.

\section{Publisher's Note}

Springer Nature remains neutral with regard to jurisdictional claims in published maps and institutional affiliations.
Ready to submit your research? Choose BMC and benefit from:

- fast, convenient online submission

- thorough peer review by experienced researchers in your field

- rapid publication on acceptance

- support for research data, including large and complex data types

- gold Open Access which fosters wider collaboration and increased citations

- maximum visibility for your research: over $100 \mathrm{M}$ website views per year

At BMC, research is always in progress.

Learn more biomedcentral.com/submissions 